\title{
Histopathological Effects of Maternal Alcohol Consumption in the Pups of Albino Rats
}

\author{
Ebugosi R.S.
}

Department of Biochemistry, Ebonyi State University, Ebonyi State, Nigeria.

\section{Okaka A.N.}

Department of Biochemistry, Faculty of Biosciences,

Nnamdi Azikiwe University Awka, Anambra State

Onochie, A. U.

Department of Biochemistry,

Chukwuemeka Oduemgwu Ojukwu University Uli, Anambra State

\section{Chukwuma G.O. \\ Manafa P.O.}

Department of Medical Laboratory Science, Faculty of Health Sciences,

Nnamdi Azikiwe University Nnewi Campus, Anambra State

\section{Ngenegbo $U$.}

Department of Biochemistry, Faculty of Biosciences,

Nnamdi Azikiwe University Awka, Anambra State

Chukwuezi F.O.

Department of Medical Laboratory Science, University of Nigeria Nsukka, Enugu State

\section{Chukwuma O.M.}

Department of Medical Laboratory Science, Faculty of Health Sciences,

Nnamdi Azikiwe University Nnewi Campus, Anambra State

doi: 10.19044/esj.2017.v13n21p368 URL:http://dx.doi.org/10.19044/esj.2017.v13n21p368

\begin{abstract}
Alcohol consumption during pregnancy and lactation periods may result to some physical and histopathological changes in offsprings. This study was undertaken to investigate the possible effects of maternal alcohol intake on the testes and accessory sex organs of male pups of albino rats. Three groups of female albino rats; A, B and C were used for this study. Group A was the control group while groups B \& C served as test groups. Eight male pups were randomly selected weekly (for five weeks) from each group and were sacrificed. The individual weights of the testes and accessory sex organs were determined and thereafter fixed in formol saline. Histopathological investigation was done and photomicrographs were taken.
\end{abstract}


There was a significant reduction $(\mathrm{P}<0.05)$ in the mean weights of the testes in the test groups compared with control in all weeks under study. In contrast a significant reduction $(\mathrm{P}<0.05)$ in the mean values of the weights of ventral lobes of prostate and epididymis were only noticed in weeks 5 and 6 while the mean value of weights of the vas deferens showed significant reduction $(\mathrm{P}<0.05)$ in week 5 of the test groups compared with control group. The histopathological results revealed that exposure to alcohol caused focal coagulative necrosis of testicular seminiferous tubules in pre-natal alcohol exposed group B and a more diffuse coagulative necrosis of testicular seminiferous tubules in pre-and post- natal alcohol exposed group C. Therefore, there is the need for controlled alcohol consumption during pregnancy and lactation periods.

Keywords: Alcohol, Maternal, Pups, Male, Reproductive, Organs

\section{Introduction}

Acute and chronic alcohol consumption have been shown to cause reproductive function derangements in human and experimental animals (Emanuele et al, 1998). Alcohol ingestion during pregnancy can result in fetal disturbances in their pups (Ethen et al, 2008). In experimental animal models the syndrome is characterized by retardation of fetal life. Fetal alcohol syndrome is a pattern of mental and physical defect that can develop in fetus in association with high levels of alcohol consumption during pregnancy (Guerri, 2002). Damage to the central nervous system (CNS) has emerged as one of the most serious consequences of fetal alcohol syndrome (Mattson and Riley, 2002). Alcohol crosses the placental barriers and can stunt fetal growth or weight, create distinctive facial stigmata, damage neurons and brain structures which can result in physiological or behavioral problems and causes other physical damage (Ethen et al, 2008). Studies in human and primates brain structure and function now strongly suggest that maternal alcohol consumption can affect fetal brain structure and functions (Clarren et al, 1978). The main effect of fetal alcohol syndrome is permanent central neurons system damage especially to the brain. Developing brain cells and structures can be malformed. Maternal alcohol exposure can create cognitive and functional disabilities including poor memory, attention deficits and impulsive behavior (Guerri, 2002). This could cause disruption of hypothalmic pituitary gonadol axis which plays a regulatory role in reproduction. Gonadotropin stimulation starts from release of lutenising hormone releasing hormone (LHRH) from hypothalamus and is released to the pituitary. In response the pituitary produces luteinizing hormone (LH) and follicle stimulating hormone FSH. LH stimulates testosterone production and FSH plays a role in sperm maturation (Emanuele et al, 1993). 
Fetal gonadotropins provide the stimulus for the maturation of fetal leydig cells and onset of testosterone secretion (Frias et al, 2002).Testosterone promotes growth, development and secretory activity of the accessory sex organs (Ogilvie and River 1997). The most complicated area is the effect of alcohol on gonadal function. Alcoholic men may have symptoms of decrease in sexual function (Anderson et al, 1987). On examination atrophic testes are found in up to half of patients with alcoholic cirrhosis and gynocosmastia is not uncommon (Jacquelyn and Maher, 1997). In alcoholic men, investigations revealed decreased total serum testosterone, increased sex hormone binding globulin and decreased free testosterone levels (Van Thiel et al, 1981). In adults, alcohol is known to disturb many of the rhythms of neuroendocrine functions, probably through its actions on the hypothalamus (Emanuele et al, 1993). This could be as a result of disruption of the hypothalamic pituitary gonadal axis.

In chronic alcohol groups of male rats it was observed that testicular, prostate and seminal vesicle atrophy occurs in addition to lowered plasma testosterone (Yen and Jaffe 1991). Some biochemical studies on chronic alcoholics showed lowered luteinizing hormone, increased $\beta$ endorphin and prolactin in male (Eriksson et al, 1994).

The histological studies of the testes obtained from chronic alcoholics demonstrate a reduction in the cross sectional area of the semineferous tubules as well as marked reduction in the number and kind of germ cells they contain. Also Alcohol can enhance apoptosis of the germ cells and be critical to healthy spermtogenesis (De Rooji, 1998).

Since the endocrine mechanism in the fetus is similar to adults, (Hadley, 1998), alcohol may disrupt the fetal neuroendocrine function by its action on hypothalamus causing disruption of the hypothalamic pituitary gonadol axis as it does in adults. Alcohol consumption has been found to have considerable effect on the liver (Jacquelyn and Maher, 1997). This has aroused serious medical interest. Alcohol has been found to injure the nervous system by inhibiting growth processes. It can attack the brain function and may have metabolic effects on the liver function enzymes. The liver is an important organ in drug metabolism (Utu Baku et al, 2009). Alcohol consumption may bring about changes that may alter the release of aspartate transaminase (AST), alanine transaminase (ALT) and alkaline phosphatase (ALP) from the liver to the peripheral blood. Heavy drinking is associated with major liver diseases such as fatty liver, alcoholic hepatitis and cirrhosis (Carguilo, 2007). It has been established that alcoholics have a tendency to develop anaemia, thrombocytopenia and many other blood disorders (Oduola et al, 2005).

Although, moderate consumption of alcohol can help improve cardiovascular health, heavy drinking can increase the amount of 
triglycerides in the blood. This can increase the risk of heart diseases, high blood pressure, and obesity and type 2 diabetes mellitus (Adam, 2011). Studies have shown that subjects with high alcohol consumption have high level of serum triglycerides, high density lipoprotein cholesterol (HDL), uric acid, estimated creatinine clearance rate $(\mathrm{CCr})$ and glomerular filterate rate(GFR) values than non drinkers (Fu-mei et al, 2005). Also alcohol reduces functional hepatic nitrogen clearance and acutely down regulates urea synthesis in normal men (Aaqaard et al, 2004).

Alcohol consumption has been shown to cause some damages in the brain, central nervous system and reproductive functions (Aguirre et al, 1995).

One of the pharmacological actions of alcohol is to lower blood glucose. While moderate amounts of alcohol can cause blood glucose to rise, excess alcohol can actually decrease blood glucose (America diabetes association, 2010). Alcohol has direct effect on the glucose levels of diabetics. Alcohols like beer and sweet wine contain carbohydrate and may raise the glucose levels on diabetics.

The purpose of this work is to determine the possible effect of maternal alcohol consumption on the testes and accessory sex organs of their offsprings.

\section{Materials and methods}

Chemicals

Twenty percent ethanol was prepared from absolute ethanol $(99 \% \mathrm{v} / \mathrm{v})$ manufactured by BDH chemicals Poole England.

\section{Animal Selection and Grouping.}

The animals (albino rats) were randomly selected at the weaning age of twenty one (21) days from a colony of inbred rats maintained for research in the animal house of university of Nigeria. Thirty virgin female and 15 immature male rats were used.

\section{Research design}

The female albino rats were grouped into three $(A, B, \& C)$ with 10 animals in each group. Group A served as control while groups B and C were used as test groups. The animals were allowed to acclimatize for 3 weeks. All the groups were fed with water and commercial rat diets. The investigations commenced at the end of six weeks which is the age of sexual maturation. During investigation, the control group A was fed with water and commercial rat diets while groups B and C where fed with $1 \mathrm{ml}$ of $20 \%$ ethanol per $\mathrm{kg}$ weight daily for 3 weeks through gastric intubation. The three 
groups where bred by using 1 male per cage of 2 females. Day 1 of pregnancy was presumed after observation of vaginal plug.

Following the diagnosis of pregnancy, groups $\mathrm{B}$ and $\mathrm{C}$ continued to receive $1 \mathrm{ml}$ of $20 \%$ alcohol until delivery. After delivery alcohol for group B was replaced with water. This group is named prenatal alcohol alcohol exposed group. while group C continued to receive $1 \mathrm{ml}$ of $20 \%$ ethanol till weaning their pups at 21 days. This group is called post natal alcohol exposed.

A total of 150 male pups of the albino rats were used to carry out the work. Thirty rats died at various stages of the investigations. Only 120 male pups were finally used to carry out the investigations. The tests were carried out every week for 5 weeks. In each week, 24 male pups were randomly selected, 8 from each group.

\section{Measurement of Weights}

The male pups which were randomly selected were sacrificed, the paired testes were dissected out and their weights determined using Metler analytical balance. The weights of other accessory sex organs ie ventral lobe of prostate, epididymis and vas deferense were determined from the third to six weeks of weeks of age using the same metler analytical balance.

\section{Histological Investigations}

After determining weights the testes and other accessory sex organs were fixed in formol acetic acid solution which contains formaldehyde, glacial acetic acid and 70\% alcohol. They were dehydrated in series of graded ethanol after which they are cleaned in xylene and embedded in paraffin. Sections of $6 \mu \mathrm{m}$ in thickness were cut using rotary microton and stained with haematoxylin and eosin. A calibrated eye piece micrometer was used. The diameter of 25 randomly selected semineferous tubules of the testes in each group was measured in micrometer $(\mu \mathrm{m})$ The epithelium of the testes and accessory sex organs were noted and described after which a photomicrograph were taken using a computer.

\section{Statistical Analysis}

Data collected were subjected to statistical analysis using the analysis of variance (ANOVA).

Values were deemed significant if $\mathrm{p}<0.05$.

\section{Results}

\section{Testicular weights of Pups}

The testicular weights of the control group weighed significantly higher at weeks 345 and 6 weeks of age than the testicular weights of test groups B 
and C. The pre-natal group B weighed more than pre- and postnatal groups C. Group $\mathrm{C}$ had the lowest mean weight.

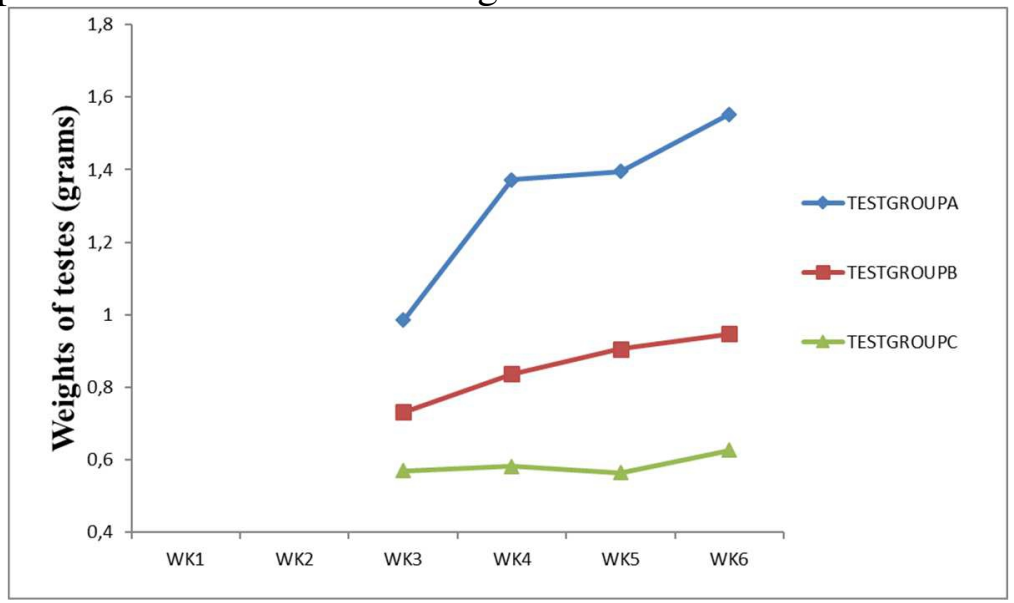

\section{Age in weeks}

Fig 1: Effect of maternal alcohol consumption on the testicular weights of the Pups of test animals compared with control groups. There were significant reduction in weights of test animals $(\mathrm{P}<0.05)$ in weeks $3,4,5$ and 6.

Keys:

TESTGROUPA=Mean weight of testes of control group A

TESTGROUPB $=$ Mean weight of testes of test group $B$

TESTGROUPC $=$ Mean weight of testes of test group $\mathrm{C}$

\section{Weights Of Ventral Lobes Of Prostate Of The Pups}

The mean values showed no significant differences in the mean weights of ventral prostate in weeks 3 and 4 .

The prostate mean weight was significantly lower in test groups B and $\mathrm{C}$ compared with control group $\mathrm{A}$.

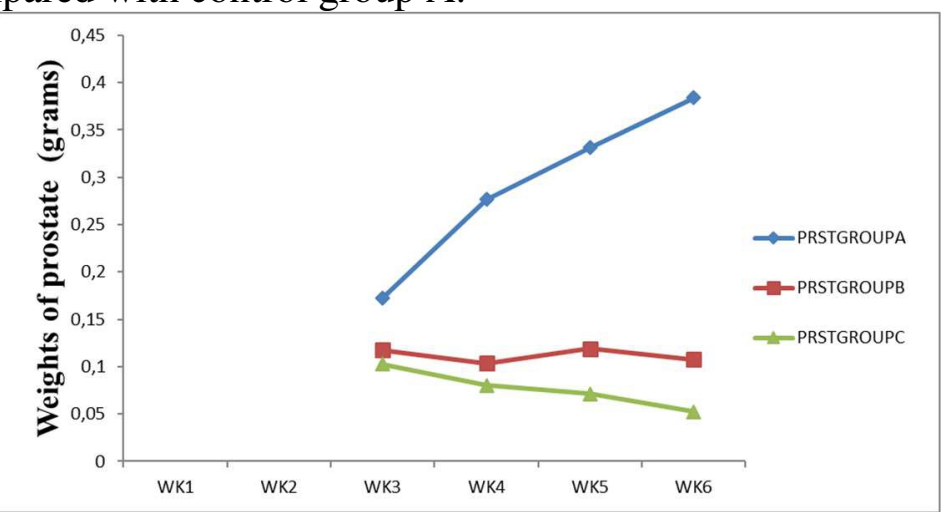

\section{Age in weeks}

Fig 2: Effects of maternal alcohol consumption on the ventral prostate of the Pups. There were significant reduction in weights of test groups B and C compared with control group A. 
Keys:

PRSTGROUPA=Mean weights of ventral prostate of control group A.

PRSTGROUPB=Mean weight of ventral prostate of test group B.

PRSTGROUP $=$ Mean weight of ventral prostate of test group C.

\section{Weights of epididymis of the pups}

Analysis of mean weights showed no significant differences in the weights of the epididymis in albino rats in weeks 3 and 4 but significant difference in weeks 5 and 6 were indicated.

The mean values of the weights of the epididymis were significantly higher in control group A than test groups B and C in weeks 4, 5 and 6.

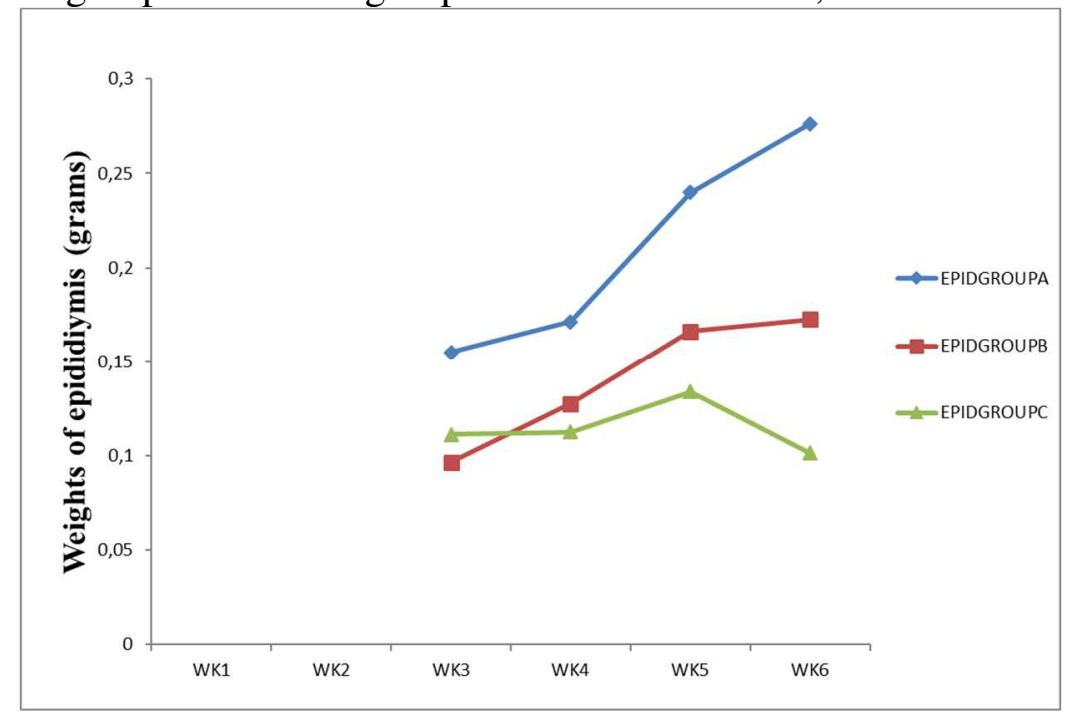

\section{Age in weeks}

Fig 3: Effect of maternal alcohol consumption on the weight of epididymis of the Pups showing reduction in mean weights of test animals $B$ and $C$ in weeks 5 and 6 compared with control A. $(\mathrm{P}<0.05)$.

Keys:

EPIDGROUPA $=$ Mean weights of the epididymis of control group A EPIDGROUPB=Mean weights of the epididymis of test group B EPIDGROUP=Mean weights of the epididymis of test group $\mathrm{C}$

\section{Weights of vas deferens of the pups}

There was significant difference in the mean weights of the vas deferens in weeks 5 and 6 of test groups compared with control group A.Group $\mathrm{C}$ had the lowest mean weight $(\mathrm{P}<0.05)$. 


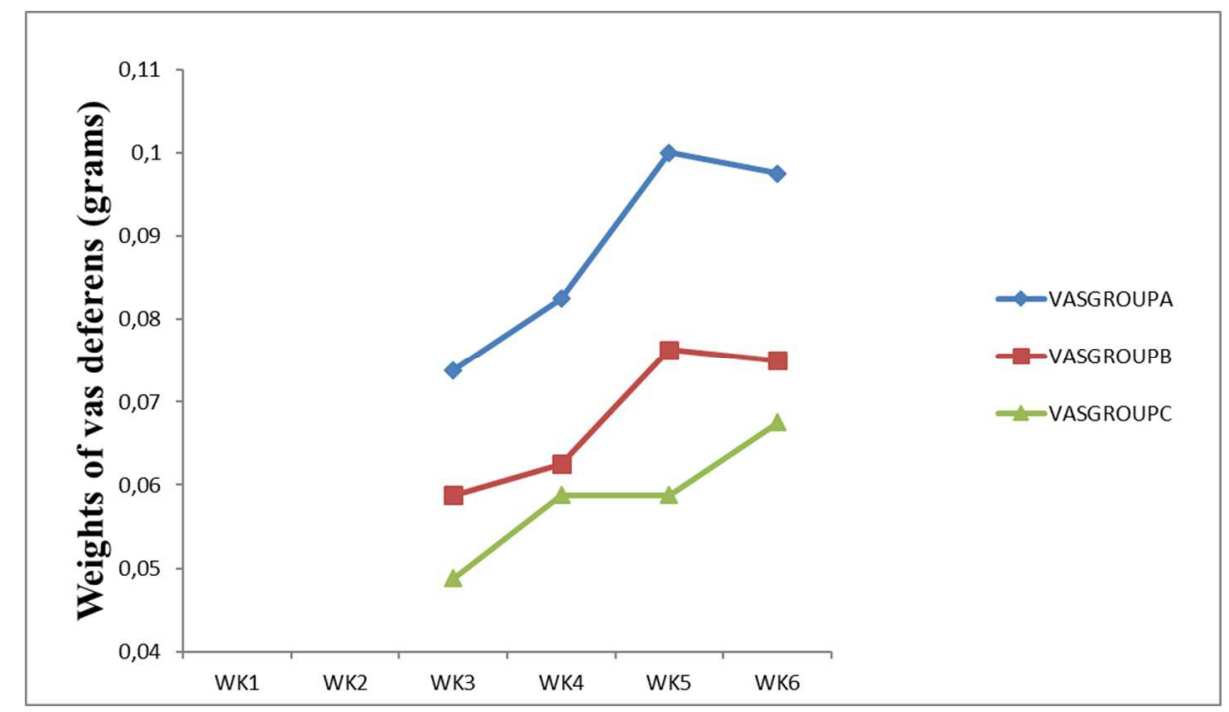

\section{Age in weeks}

Fig 4: Effect of maternal alcohol consumption on weights of vas deferens of the Pups. The mean weights of control group A is significantly higher than mean weights of groups B and $\mathrm{C}$ in weeks 5 and 6. $(\mathrm{P}<0.05)$.

Keys:

VASGROUPA $=$ Mean weights of vas deferens of control group A VASGROUPB=Mean weights of vas deferens of test group B VASGROUP $=$ Mean weights of vas deferens of test group $\mathrm{C}$

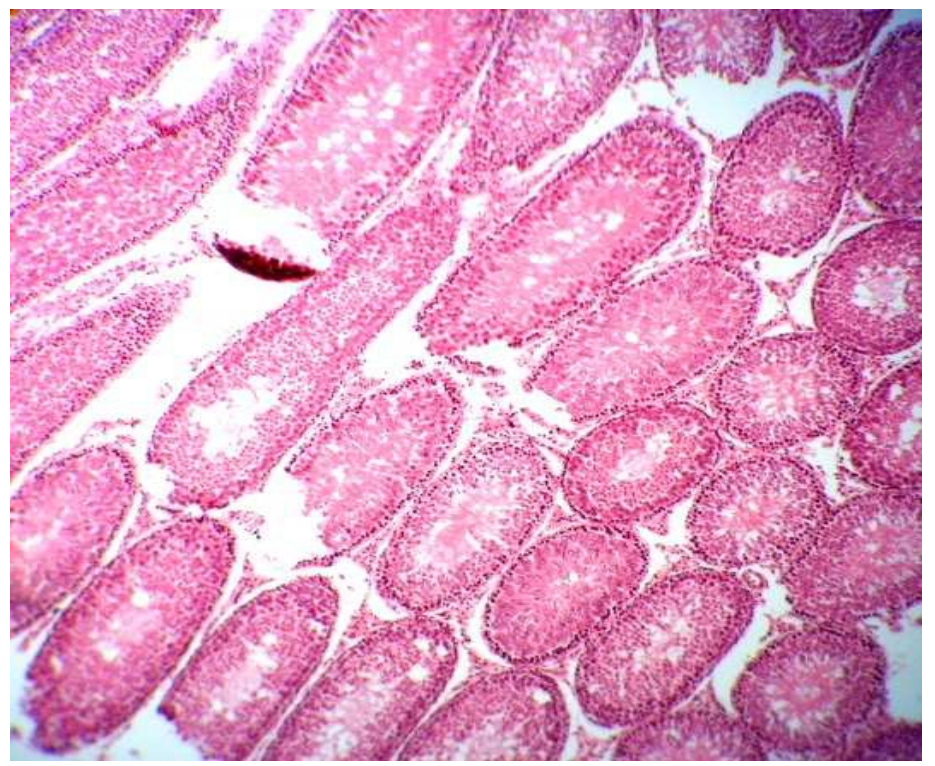

Fig 5: Photomicrograph of testis of control rats (Group A) showing unremarkable lobules of testicular seminiferous tubules (H \& E stain; x 100).

Sections of the control rats are moderately circular or oval in outline with normal stratified seminiferous epithelium 


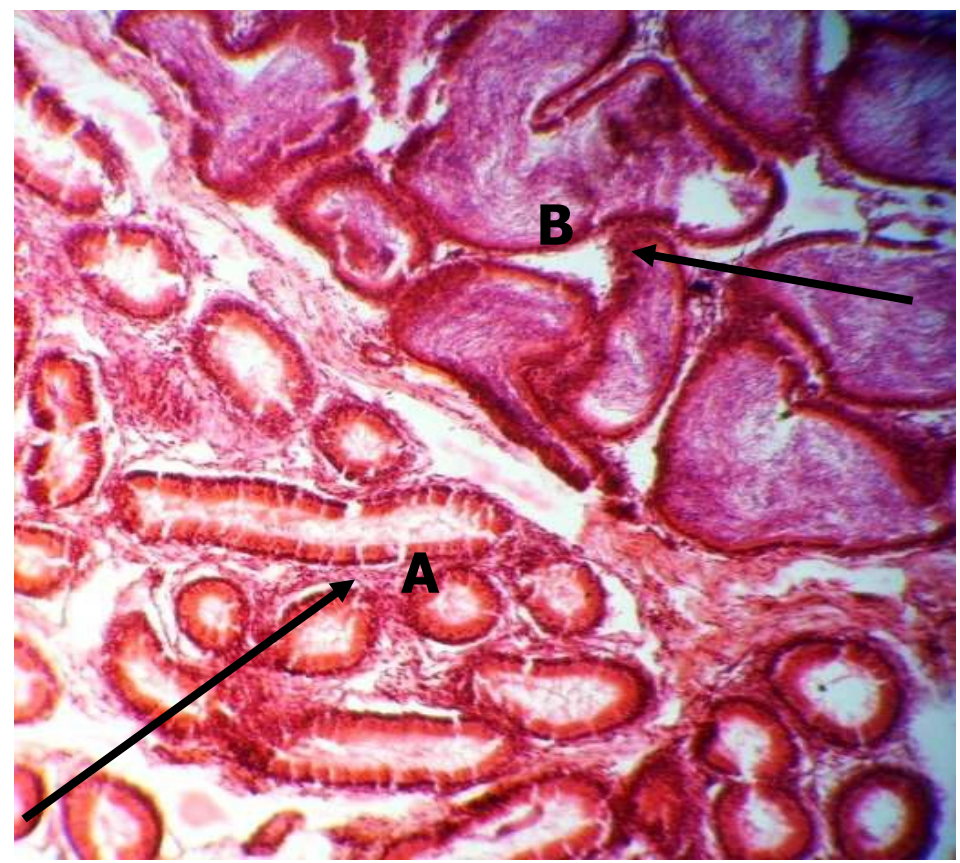

Fig 6: Photomicrograph of testis of control rats (Group A) showing unremarkable lobules of testicular seminiferous tubules (arrowed A) and tubules of ductus epididymis (arrowed B) (H \& E stain; $x$ 100).

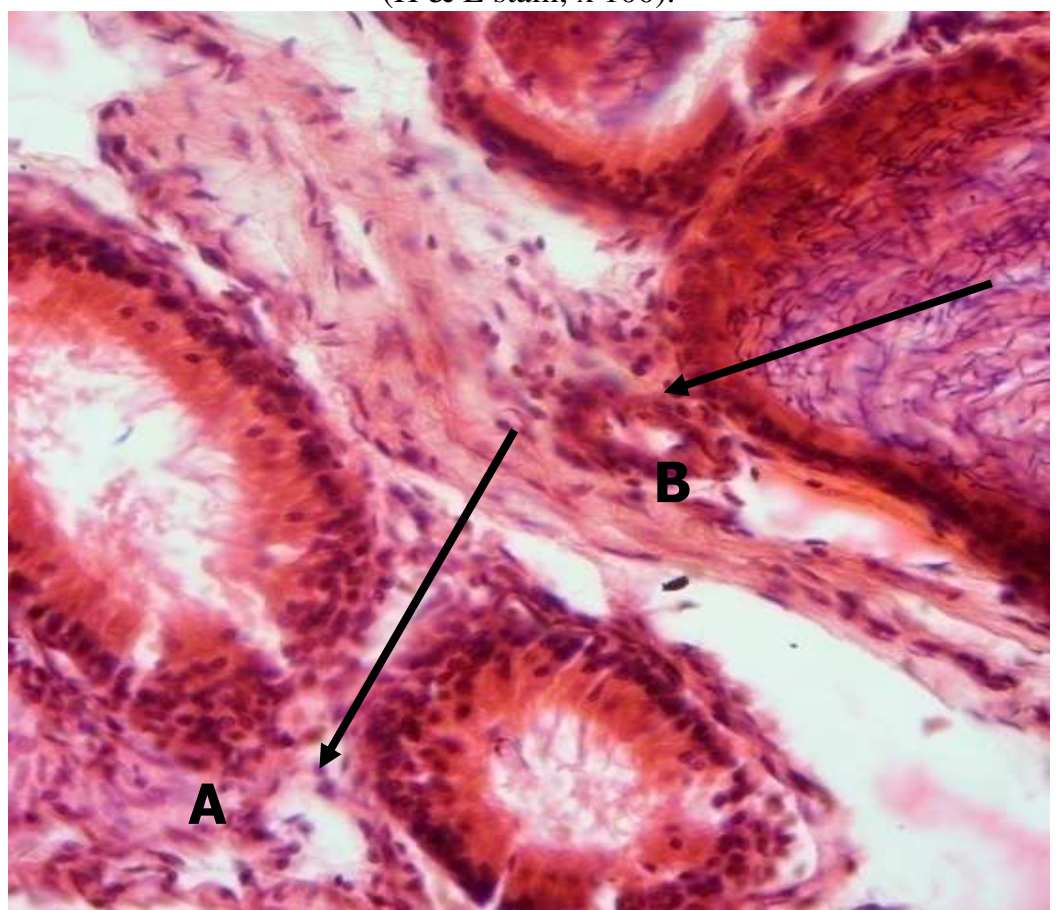

Fig 7. Photomicrograph of testis of control rats (Group A) showing unremarkable lobules of testicular seminiferous tubules (arrowed A) and tubules of ductus epididymis (arrowed B)

(H \& E stain; $x$ 400). 


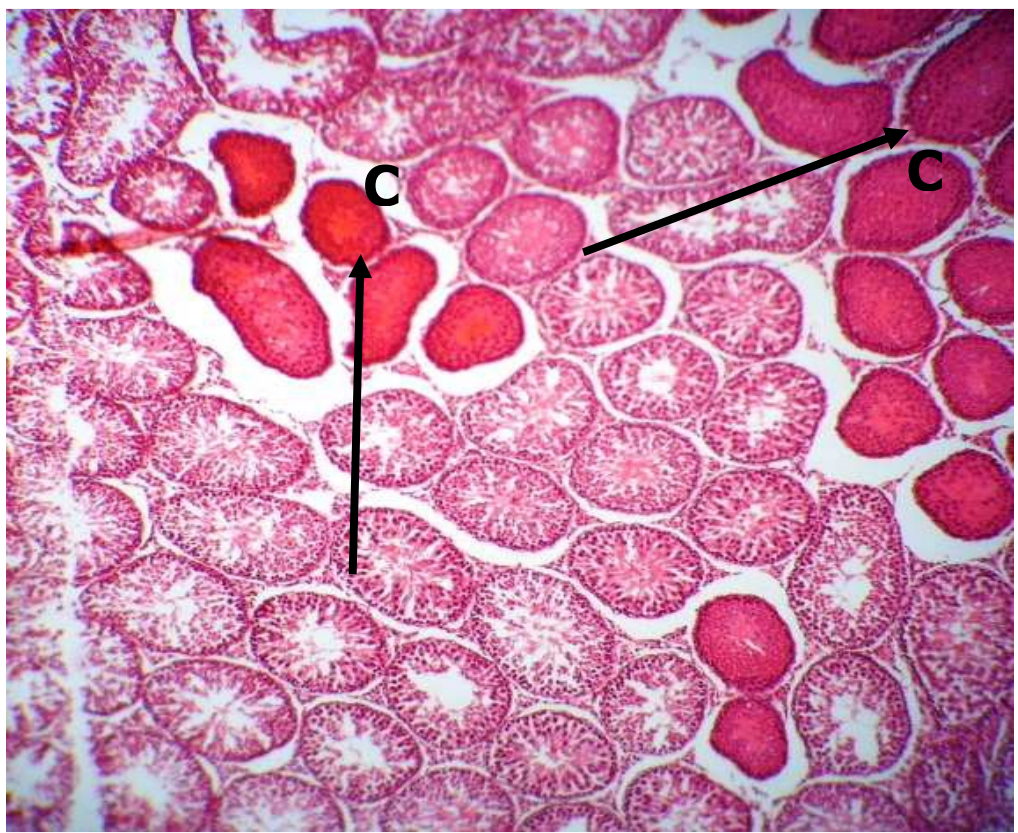

Fig 8. Photomicrograph of testis of experimental rat (prenatal alcohol exposed group B) administered $1.0 \mathrm{ml}$ of $20 \%$ ethanol showing a focal coagulative necrosis of testicular seminiferous tubules (labeled C) (H \& E stain; x 100).

Sections of semineferous tubules are elongated and distorted. The tubular lumen are wide with tubular necrosis.

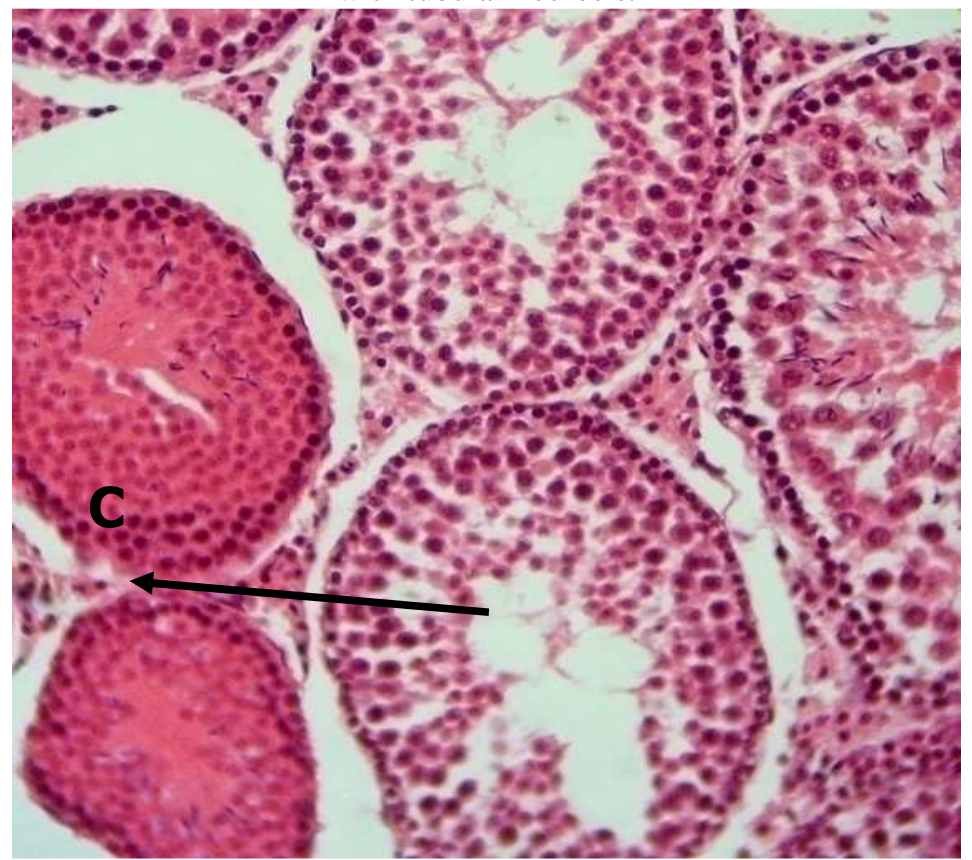

Fig 9. Photomicrograph of testis of test rat (prenatal alcohol exposed group B) administered $1.0 \mathrm{ml}$ of $20 \%$ ethanol showing a focal coagulative necrosis of testicular seminiferous tubules (labeled C) (H \& E stain; x 400). 


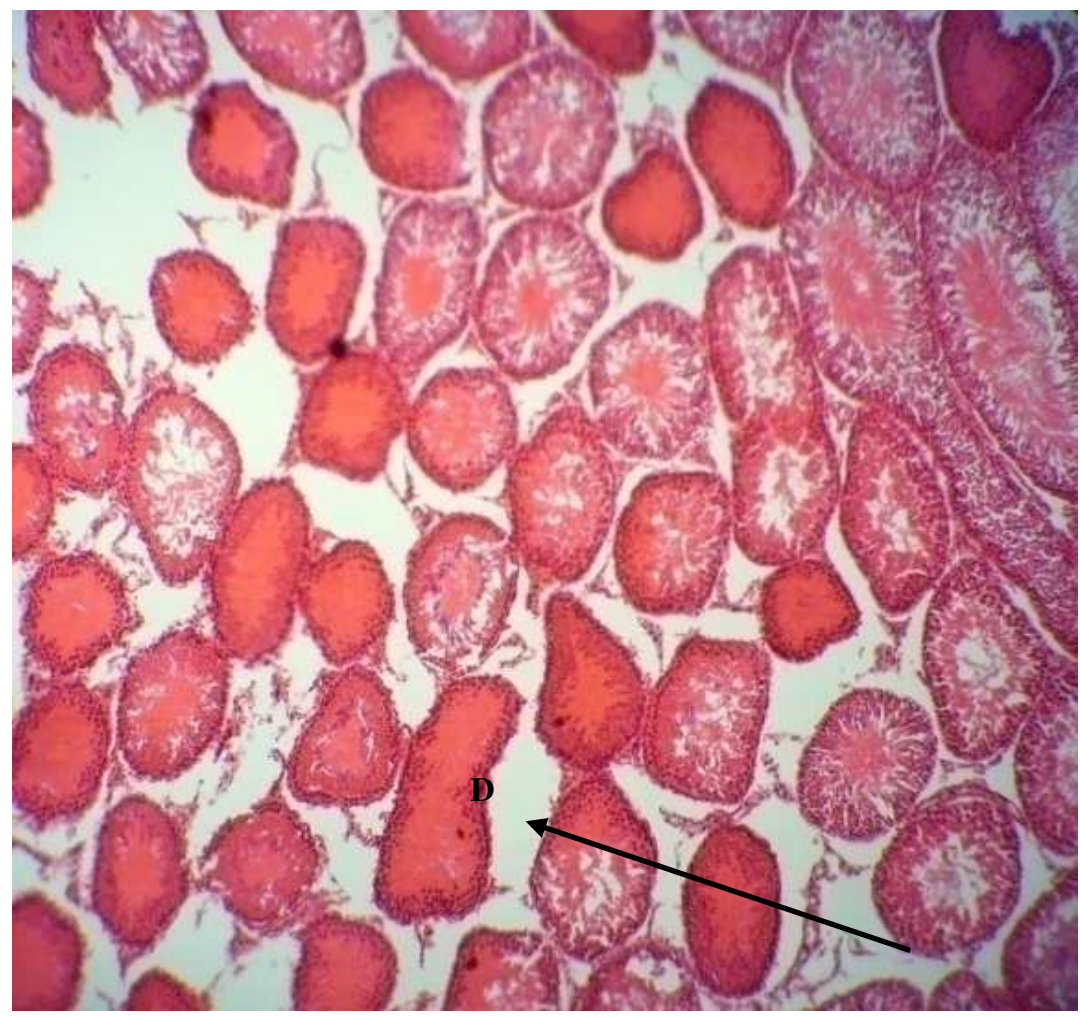

Fig 10. Photomicrograph of testis of test rats (Pre- and postnatal alcohol exposed group C) administered $1.0 \mathrm{ml}$ of $20 \%$ ethanol showing more diffuse coaguative necrosis of testicular seminiferous tubules (arrowed D) (H \& E stain; x 100).

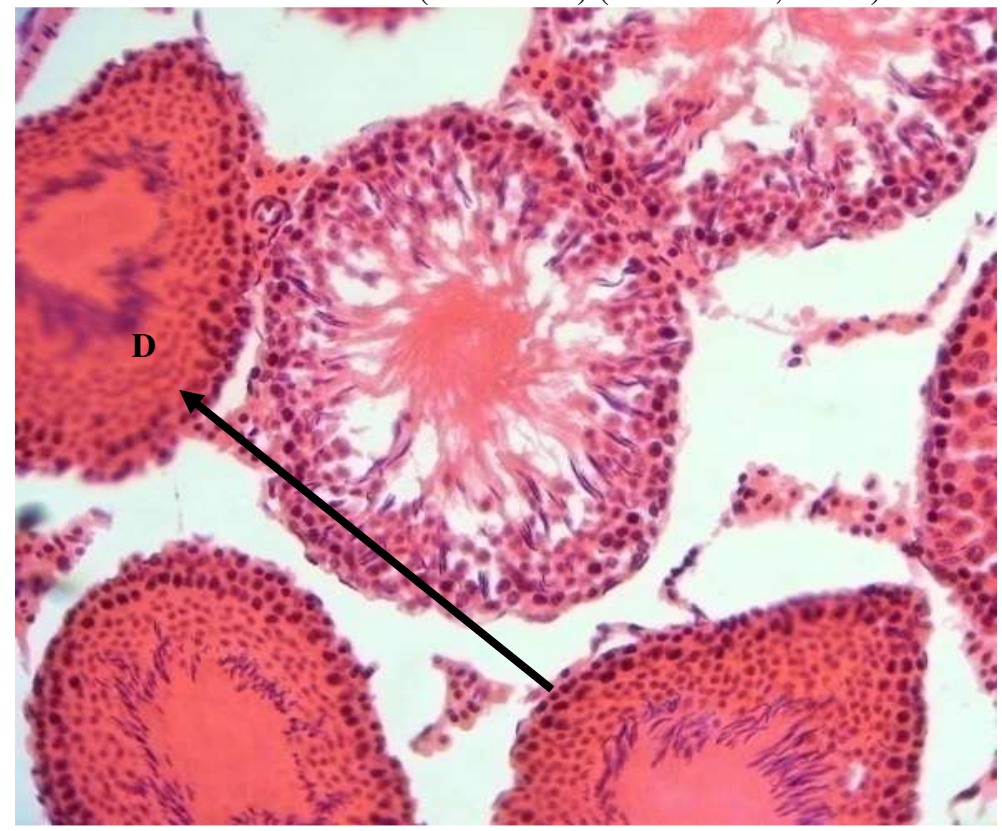

Fig 11. Photomicrograph of testis of test rats (Pre- and postnatal alcohol exposed group C) administered with $1.0 \mathrm{ml}$ of $20 \%$ alcohol showing more diffuse coagulative necrosis of testicular seminiferous tubules (labeled D) (H \& E stain; x 400). 


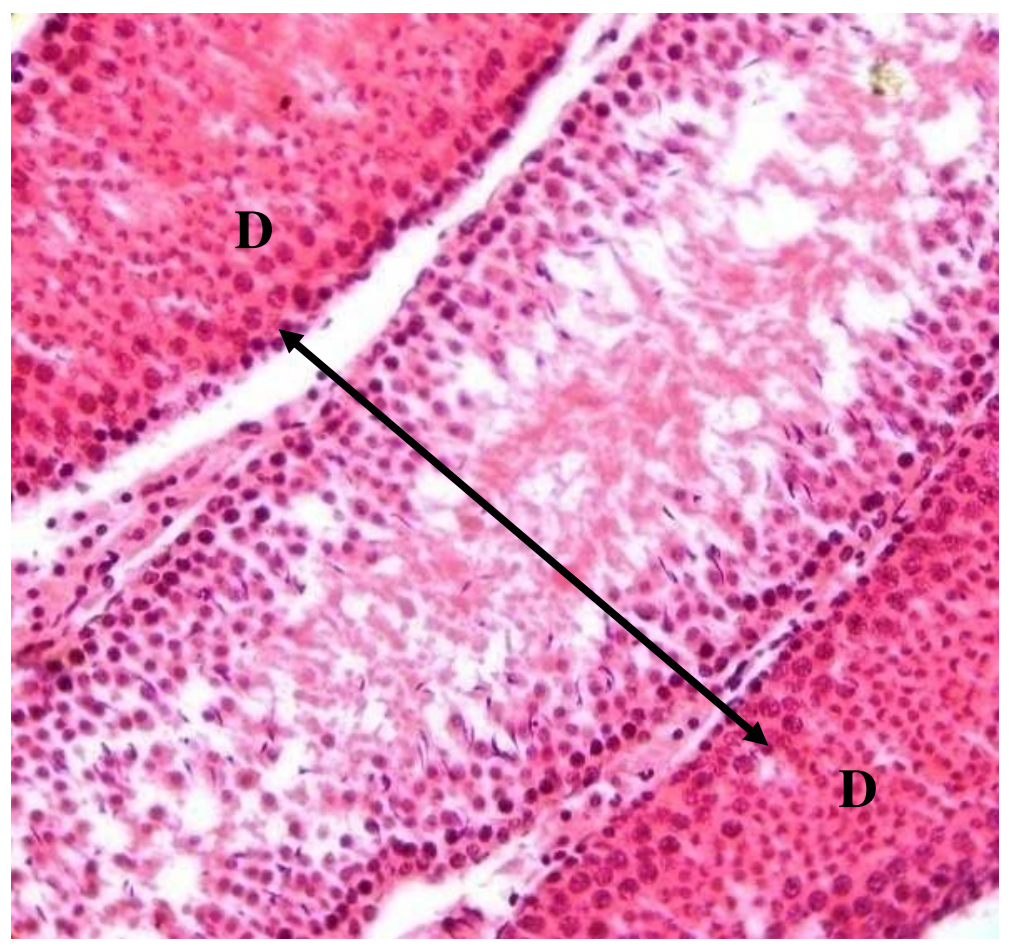

Fig 12. Photomicrograph of testis of test rats (Pre- and postnatal alcohol exposed group C) showing a more diffuse coagulative necrosis of testicular seminiferous tubules (D) (H \& E stain; $\mathrm{x} 400$ ).

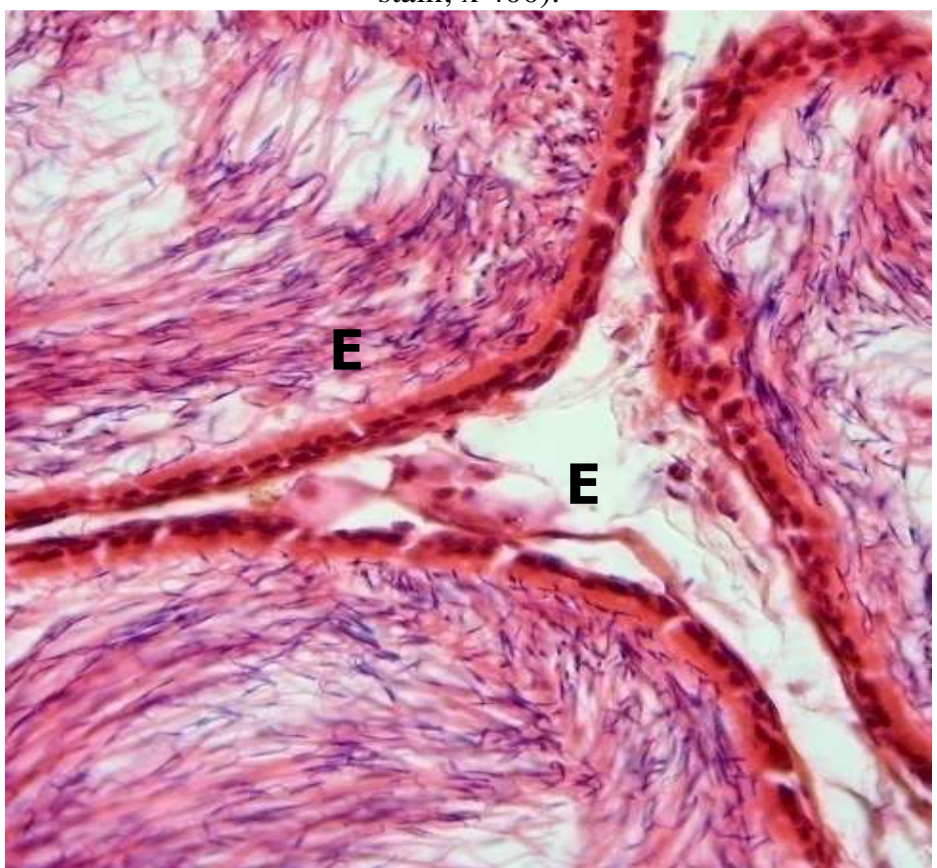

Fig 13. Photomicrograph of testis of control rats (Group A) showing unremarkable tubules of ductus epididymis filled with sperm (labeled E) (H \& E stain; x 400). 


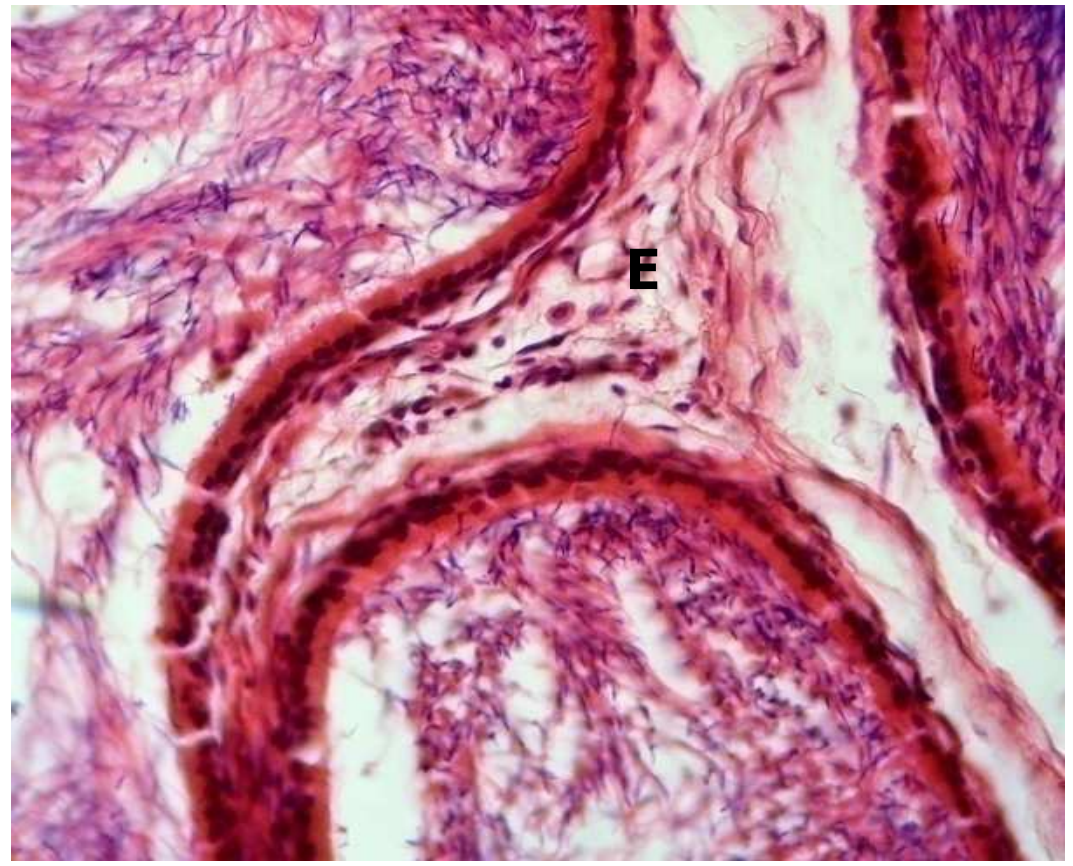

Fig 14. Photomicrograph of testis of test rats (pre-natal alcohol exposed group (B) showing unremarkable tubules of ductus epididymis filled with sperm (labeled E) (H \& E stain; $\mathrm{x}$ 400).

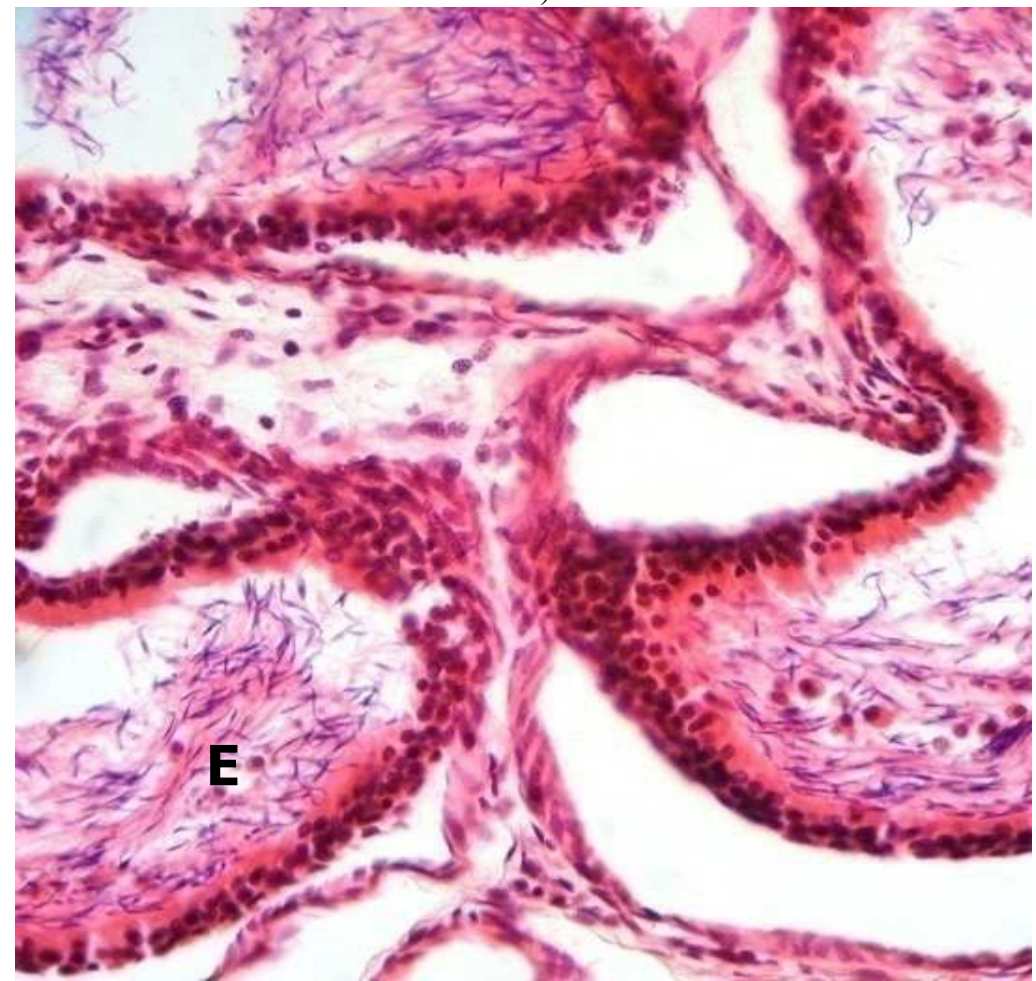

Fig 15. Photomicrograph of testis of test rats (Pre- and postnatal alcohol exposed group C) showing unremarkable tubules of ductus epididymis filled with sperm (labeled E) (H \& E stain; $\mathrm{x} 400)$. 


\section{Discussion}

Alcohol consumption reportedly affect male reproductive system and result in testicular injury (Kelce et 1990). This investigation demonstrated that maternal alcohol consumption during pregnancy and lactation periods caused weight reduction in testes and other accessory sex organs of the pups. The marked reduction in weights of the testes of pups of rats exposed to alcohol was in line with what was described as lack of catch up growth in fetal alcohol syndrome in experimental animals (Hanson et al, 1976). Reduced growth has been reported on the testes of alcohol exposed mature rats \{(Onu and Ezeasor, 2001), (Onu et al, 2002) and (Fakoya and CaxonMartins, 2004)\}. This work recorded higher weight loss in groups exposed to alcohol during pregnancy and lactation periods compared with groups exposed to alcohol only during pregnancy. The lower testicular weight difference of this group over the group exposed to alcohol only during pregnancy would appear to be as a result of exposure of this group to alcohol during pregnancy and lactation period. This observation was similar to the findings of (Onu et al, 2002). Our work reported that alcohol intake in rats during pregnancy and lactation periods retarded the growth of the epididymis of their pups. Weights of the epididymis of a control group are significantly bigger than the weights of the of pre-natal and postnatal exposed group. Consequently the weights of pre-natal alcohol exposed group is bigger than that of pre \& post alcohol exposed group. The increase in the weight of epididymis of pups exposed to alcohol during pregnancy only, over those exposed to alcohol during pregnancy and lactation showed that alcohol ingestion during pregnancy and lactation periods produce adverse cumulative effect on the growth of epididymis. This has gone further to confirm that persistent exposure affects the weight of the accessory sex organs. The suppressive effect of ethanol on the weight of the epididymis of pups is in agreement with earlier reports of \{(Shrinkanth et al, 1999), (Nwaogu and Ihemelendu 1999) and (Kathryn et al, 1986)\}, who recorded suppressive effect of alcohol on the growth of the epididymis of mature rats. Despite reduction in weights of the epididymis of the experimental animals of group $\mathrm{B}$ and $\mathrm{C}$, the tubules were unremarkable, ductus intact and filled with sperm cells for testicular cells that were not necrotic as in figs 13 and14. These findings differ slightly from works of Dosumu et al,2010, who reported decreased spermatozoa in tubular lumen.

The weights of vas deferens of the pups showed no changes in weeks 3 and 4 but constant exposure to alcohol to pre and postnatal group gave a significant weight change. This is similar to the observation by Kathryn et al, 1986, alcohol consumption affects the weight and contraction of the smooth muscle of vas deferens. One of the deleterious effects of alcohol consumption on the testes could be a change in the structure of mitochondria. 
Chronic ethanol ingestion results in elongation and distortion of the mitochondria. This may appear as swollen or elongated structures with cristae often distorted without normal size (Kiessling and Tobe, 1964). Ethanol ingestion results in alteration in mitochondrial ribosomes making them less functional (Coleman and Cunningham, 1991). This will lead to enzyme inactivation as a result of depression in translation of the oxidative phosphorylation associated with peptides (Coleman and Cunningham, 1990). The result of these alterations may promote both apoptosis and necrosis promoting testicular damage as shown in figs 8,9 and10. Heavy alcohol consumption over long periods of time results in severe cell damage that leads to cell death. Cell death occur by necrosis or apoptosis. Exposure of cells to alcohol causes loss of the cells metabolic functions and result to the damage processes by activating a cascade of biochemical reactions that ultimately lead to cell shrinkage and fragmentation of the nucleus. When a cell undergoes apoptosis, the entire cells including the nucleus separates into fragments. Focal coagulative necrosis recorded in pre-natal alcohol exposed group could be due to loss of cell functions and damage resulting from a cascade of biochemical reactions that led to cell shrinkage and fragmentation. A more diffuse coagulative necrosis observed in pups of rats exposed to alcohol during pregnancy and lactation periods revealed the deleterious effects of alcohol on the testicular cells. Our findings are in line with those of Onu et al, 2002 and Oglivie and Rivier, 1997. The association between chronic alcohol ingestion and male reproductive failure in rats have been well documented (Martinez et al, 1995), (Van Thiel et al, 1981) and (Fakoya and Caxon-Martins, 2004)\}. Analysis of histological appearance of testes indicated that there was delay in the maturation of spermtogenic cells in the alcohol exposed groups as a result of necrosis of testicular seminiferous tubules. Follicle stimulating hormones (FSH) as well as testosterone are required for the induction of spermatogenesis. Frias et al, 2002 have demonstrated that follicle stimulating hormone (FSH) is essential for the later stages of spermatogenesis.

In this work the epididymis of the offsprings of alcohol exposed groups are not affected however work carried out by Shrinkant et al, 1999, on adult rats showed that alcohol affected the epididiymis and sperm maturation. It has been observed that alcohol during pregnancy adversely affects the regulation mechanism of growth of offsprings and the effect persisted after birth \{(Lolyed-Still, 1976), (Leichterand Lee, 1999) and (Taylor, 1984)\} observed that alcohol impaired the fetal hormonal system. The retardation of growth of testes and accessory sex organs could be as a result of impairment of fetal hormonal system as a result of disruption of hypothalamic pituitary gonadal axis (Onu et al, 2010). In conclusion this study demonstrates that maternal alcohol consumption during pregnancy and 
lactation periods would result in some deleterious effects in the reproductive organs of their pups.

\section{References:}

1. Aaqaard, N. K., Thqeresen, T., Greisen, J., and Vilstrup, H. (2004). Alcohol acutely down- regulates urea synthesis in normal men. Alcohol, Clinical Experimental Research. 28, (5): 697 - 701.

2. Adam, Cloe. (2011).The Effects of Alcohol on Cholesterol levels. American Journal of Pharmacology. 67, (6) 230 -240.

3. Aguirre, J. C., Del-Arbol, J.L., Rico, J., Raya, J., and Ruiz, E. (1995). Effect of acute alcohol intoxication on the opioid system in humans. Alcohol. 12. 559-562.

4. American Diabetes Association, (2010). High blood glucose and diabetes complication: the buildup of molecules known as AGEs may be the key link.

5. Anderson, J. R., Willis, B. R., and Philips, J. F. (1987). Delayed pubertal development of the male reproductive tract associated with chronic ethanol ingestion. Biochemical Pharmacology. 36: 21572167.

6. Carguilo, T. (2007). Understanding the health impact of alcohol dependence. American Journal of Health System Pharmacology. 64 (5):85-87.

7. Clarren, S., Alvovrd, E., Sumi, S., Streissguth, A., and Smith, D. (1978). "Brain malformations related to prenatal exposure to ethanol". Journal Pediatric 92(1): 64-67.

8. Coleman, W.B. Cunningham, C.C. (1991). Effect of chronic ethanol consumption on hepatic mitochondrial transcription and translation. Biochim Biophys Acta, 1058 pp. 178-186.

9. Coleman, W.B., Cunningham, C.C. (1990). Effect of chronic ethanol consumption on the synthesis of polypeptides encoded by the hepatic mitochondrial genome. Biochem Biophys Acta, 1019 pp. 142-150.

10. De Rooij, D. G. (1998). Stem cells in the testis. International Journal Experimental Pathology. 79: 67 - 80.

11. Dosumu, O.O. ( 2010). Histomorphometric studies of the effects of coconut (Cocos nucifera) oil on alcohol-induced testicular injury in Sprague-Dawley rats. Ph.D. Thesis, University of Lagos, Lagos, Nigeria.

12. Emanuele, M.A., La Paglia, N., Jabamoni, K., Hansen, M., Kirsterns, L., and Emanuele, N.V. (1998). Reversal of chronic ethanol -induced testosterone suppression in prepubertal male rats by opiate blockade Alcoholism. Clinical and Experimental Research. 22: 1199-1204. 
13. Emanuele, M.A., Halloran, M.M., Uddin, S., Tentler, J.J., Emanuelle, N.V., Lawrence, A.M., and Kelly, M.R. (1993). The effects of alcohol on the neuro endocrine control of reproduction. In: Alcohol and the Endocrine System. Zakhari, $5^{\text {th }}$ edition, National Institute of Health Publications, Bethesda, M.D. 89-116.

14. Eriksson, C.J.P., Fukunaga, T., and Lindman, R. (1994). Sex hormone to alcohol. Nature. 369:711.

15. Ethen, M. K, Ramadhani, T. A, Scheuerle, A. E. et al. (March 2008). "Alcohol Consumption by Women Before and During Pregnancy". Maternal and Child Health Journal 13 (2): 274-85. doi: $10.1007 / \mathrm{s} 10995-008-0328-2$. PMID 18317893.

16. Fakoya, F. A. and Caxton-martins, E. A. (2004). Morphological alterations in the seminiferous tubules of adult wistar rats: the effect of prenatal ethanol exposure. Folia Mor-phologica. 63 (2): 195-202.

17. Frias, J., Torres, J.M., Miranda, M.T., Ruiz, E., and Ortegan, E. (2002). Effects of acute alcohol intoxication on the pituitary gonadal axis hormones, $\beta$-endorphin and prolactin in human adults of both sexes. Alcohol and Alcoholism. 37: ( 2) 169-173.

18. Fu-mei, C., Yi-Hsin, Y., Tien-Yu, S., Shyi-Jank, S. J., Tsai, C-R., and Yau-Jiunn L. (2005). Effect of alcohol on estimated glomerular filtration rate and creatinine clearance rate. Nephrology Dialysis Transplant. 20: 1610-1616.

19. Guerri, C. (2002). Mechanisms involved in central nervous system dysfunctions induced by prenatal ethanol exposure. Neurotoxicity Research, 4 (4): 327-335.

20. Hadley, M.E. (1998). Endocrinology. Second Edition. Englewoods Cliff, N. J. Prentce Hall.

21. Hanson, J.W., Jones, K.L., and Smith, D.W. (1976). Fetal Alcohol syndrome. Experience with 41 patients. Journal of American Medical Association. 235: 1458-1460.

22. Jacquelyn, J., and Maher, M.D. (1997). Exploring alcohol effects on liver function. Alcohol, Health and Research World. 21 (1):5-12.

23. Kathryn, H., and Deturk, Larissa A., Pohorecky. (1986). Development of tolerance to the inhibitory effects of ethanol in the rat isolated vas deferens. Effect of acute and chronic ethanol administration invivo. British Journal of Pharmacology. 88: 397403.

24. Kelce, W.R., Ganjam, V.K., Rudeen, P.K. (1990) Inhibition of testicular steroidogenesis in the neonatal rat following acute ethanol exposure. Alcohol, 7 pp. 75-80.

25. Kiessling, K.H., Tobe, U. (1964). Degeneration of liver mitochondria in rats after prolonged alcohol consumption. 
26. Leichter, J., and Lee, M. (1979). Effects of maternal ethanol administration on physical growth of offspring in rats. Growth. 43: 288 - 297.

27. Lolyed-Still, J.D. (1976). Malnutrition and Intellectual development. $3^{\text {rd }}$ edition Publishing Services Group incorporated Philadelphia.102-106.

28. Martinez, F.E., Garcia, P.J., Padovani, C.R., Cagnon, V.H.A., and Martinze, M. (1995). Effect of experimental chronic alcoholism on the reproductive system of the male rat. Brazilian Journal of Morphology. 12:143-148.

29. Mattson, S. N. and Riley, E. P. (2002). "Neurobehavioral and Neuroanatomical Effects of Heavy Prenatal Exposure to Alcohol," in Streissguth and Kantor. (2002). p. 10.

30. Nwaogu, I.C., Ihemelandu, E.C. (1999a). effect of alcohol consumption on the allometric growth of muscles in fetal and neonatal rats. Cells Tissues and Organs. 164: 167-172

31. Oduola, T. O. G. Adesun, T. A. Odula, N. R. Agbaje and Raheem Z. A. (2005). Biochemical and haematological findings in alcohol consumers in lle lfe, Osun-state. Drinking pattern, pp: 1-4.

32. Ogilvie, K.M., and River, C. (1997). Prenatal alcohol exposure results in hyper- activity of the hypothalamic pituitary adrenal axis of the offspring: modulation by fostering at birth and post natal handling. Alcoholism: Clinical and Experimental Research. 21: 424429.

33. Onu, J. E., Ezeasor, D.N. and Ihemelandu, E.C. (2010). Effect of maternal alcohol consumption on epididymal growth in neonatal mice. Nigeria Veterinary Journal. 31 (4) 279-282.

34. Onu, J. E., Ezeasor, D. N. and Ihemelandu, E. C. and Ndondo, N. (2004). Penile growth in foetal alcohoil syndrome of mice. Phillipine. Journal Veterinary Medicine. 4. 2: 100-104.

35. Onu, J. E., Ihemelandu, E.C., Ezeasor, D.N. (2002). The effect of maternal alcohol consumption on the growth rate of body and testes in neonatal mice. Nig. J. exp. Appl. Biol. 3 (2) 159-163.

36. Onu, J. E., Ihemelandu, E.C. and Ezeasor, D.N. (2002). Testicular growth in fetal alcohol syndrome of mice. Sahal Medical Journal. 5: 47-49.

37. Onu, J.E., Ezeasor, D.N (2001). Retardation of testicular growth in mice in fetal alcholo syndrome: suspected evidence of disruption of hypothalamicpitutary gonadal axix regulation. Nigerial Vet. J. 22 (2) 35-41.

38. Shrinkanth, V., Malini, T., Arunakaran, T., Govindarajulu, P., and Balasubramanian, K. (1999). Effect of ethanol treatment on 
Epididymal Secretory products and Sperm maturation in Albino rats. The American Society for Pharmacology Experimental Therapuetics. 288 (2): 509-515.

39. Taylor, H. (1984). Minimal brain dysfunction in perspective. Advanced Clinical Neuropsychology. Tarter, H.E., Goldstein, G. (edition) Plenum press New York. 207-229.

40. Utu - Baku, A.B., Obochi, G.O., Inah, S. A., Atangwho, J.I., Ugian, E.A., Ogbeche, J.O., Idenyi, J.N., and Ukeh, D.A. (2009). The influence of alcohol kolanut constituents on liver aspartate aminotransferase and alanine aminotransferase enzyme activities on albino wistar rats. International Journal of Biological Chemistry. 3: 25-29

41. Van Thiel, D.W., Cobb, C.F., Herman, G.B., Penez, L., and Gavaler, J.S. (1981). An examination of various mechanisms for ethanol induced testicular injury: studies utilizing the isolated perfused rat testes. Endocrinology. 109: 2009-2015.

42. Yen, S. S. C. and Jaffe, R. B. (1991). eds. Reproductive endocrinology, Third edition. Philadelphia: W.B. Saunders Co. 